\title{
ACTN3 R577X and ACE I/D gene variants influence performance in elite sprinters: a multi-cohort study
}

loannis D. Papadimitriou', Alejandro Lucia ${ }^{2}$, Yannis P. Pitsiladis ${ }^{3}$, Vladimir P. Pushkarev ${ }^{4}$, Dmitry A. Dyatlov ${ }^{5}$, Evgeniy F. Orekhov ${ }^{5}$, Guilherme G. Artiolii, João Paulo L. F. Guilherme ${ }^{6}$, Antonio H. Lancha Jr ${ }^{6}$, Valentina Ginevičienè ${ }^{7}$, Pawel Cieszczyk ${ }^{8,16}$, Agnieszka Maciejewska-Karlowska ${ }^{8}$, Marek Sawczuk ${ }^{8}$, Carlos A. Muniesa ${ }^{9}$, Anastasia Kouvatsi ${ }^{10}$, Myosotis Massidda ${ }^{11}$, Carla Maria Calò ${ }^{11}$, Fleur Garton ${ }^{15}$, Peter J. Houweling ${ }^{15}$, Guan Wang ${ }^{3}$, Krista Austin ${ }^{3}$, Anastasiya M. Druzhevskaya ${ }^{12}$, Irina V. Astratenkova ${ }^{13}$, Ildus I. Ahmetov ${ }^{14}$, David J. Bishop ${ }^{1}$, Kathryn N. North ${ }^{15}$ and Nir Eynon ${ }^{\text {** }}$

\section{Abstract}

Background: To date, studies investigating the association between ACTN3 R577X and ACE I/D gene variants and elite sprint/power performance have been limited by small cohorts from mixed sport disciplines, without quantitative measures of performance. Aim: To examine the association between these variants and sprint time in elite athletes.

Methods: We collected a total of 555 best personal 100-, 200-, and 400-m times of 346 elite sprinters in a large cohort of elite Caucasian or African origin sprinters from 10 different countries. Sprinters were genotyped for ACTN3 R577X and ACE ID variants.

Results: On average, male Caucasian sprinters with the ACTN3 577RR or the ACE DD genotype had faster best 200-m sprint time than their $577 X X(21.19 \pm 0.53 \mathrm{~s}$ vs. $21.86 \pm 0.54 \mathrm{~s}, p=0.016)$ and ACE II $(21.33 \pm 0.56 \mathrm{vs} .21 .93 \pm 0.67 \mathrm{sec}$, $p=0.004$ ) counterparts and only one case of ACE II, and no cases of ACTN3 577XX, had a faster 200-m time than the 2012 London Olympics qualifying (vs. 12 qualified sprinters with 577RR or 577RX genotype). Caucasian sprinters with the ACE DD genotype had faster best 400-m sprint time than their ACE II counterparts (46.94 $\pm 1.19 \mathrm{~s}$ vs. $48.50 \pm 1.07 \mathrm{~s}, p=0.003)$. Using genetic models we found that the ACTN3 577R allele and ACE D allele dominant model account for $0.92 \%$ and $1.48 \%$ of sprint time variance, respectively.

Conclusions: Despite sprint performance relying on many gene variants and environment, the $\%$ sprint time variance explained by ACE and ACTN3 is substantial at the elite level and might be the difference between a world record and only making the final.

Keywords: ACTN3, ACE, Genomics, Athletic performance, Exercise, Athletes, Sprint, a-actinin-3

\footnotetext{
*Correspondence: Nir.Eynon@vu.edu.au

${ }^{1}$ Institute of Sport, Exercise and Active Living (ISEAL), Victoria University,

Victoria 8001, Australia

Full list of author information is available at the end of the article
} 


\section{Background}

Although the likelihood of becoming an elite sprint/ power athlete is likely influenced by genetic factors $[1,2]$ only a handful of genes have been associated with sprint performance. Currently the most promising candidate gene is the ACTN3, which encodes the sarcomeric protein $\alpha$-actinin-3 in skeletal muscle fibres [3]. The expression of $\alpha$-actinin-3 protein is almost exclusively restricted to fast, glycolytic, type $2 \mathrm{X}$ fibres, which are responsible for producing 'explosive', powerful contraction [4]. Homozygosity for common null single nucleotide polymorphism (577XX, rs1815739) in the ACTN3 gene results in complete deficiency of the $\alpha$-actinin- 3 protein in an estimated $18 \%$ of humans worldwide [5], and the ACTN3 RR genotype has been associated with elite sprint/power athletic performance in several independent cohorts of elite athletes [2].

A higher frequency of the ACTN3 577RR genotype (and lower frequency of the $\alpha$-actinin-3 deficient, 577XX genotype) in elite sprint/power athletes (i.e., sprinters, jumpers, and throwers) was originally found in a case (athletes):control (non-athletes) association study with Australian subjects [3]. This finding was independently replicated in Finnish [6], Greek [7], Russian [8], Israeli [9] and Japanese [10] national/international level athletes. No Olympic-level sprinter has yet been identified with the 577XX genotype $[3,7,9,11]$. Taken together, these association studies suggest that $\alpha$-actinin- 3 deficiency is detrimental to optimal fast muscle function at the extremes of sprint and power performance. In support of this, mice lacking $\alpha$-actinin-3 (Actn3 knockout mice, mimic the 577XX genotype in humans) demonstrate a shift in the physiological and metabolic properties of 'fast' glycolytic muscle fibres (type 2B) towards a slower, oxidative muscle phenotype (types 1 and $2 \mathrm{~A}$ ), which are responsible for postural and endurance activities [12] and ACTN3 577XX humans show lower proportion of fast-twitch muscle fibers $[13,14]$ and lower levels of testosterone [15].

Another candidate gene associated with elite performance is the $A C E \mathrm{I} / \mathrm{D}$. Besides regulating blood pressure, $A C E$ may influence skeletal muscle function [16]. Indeed, ACE catalyses the conversion of the vasoconstrictor agent angiotensin I into, angiotensin II, which not only as a more potent vasoconstrictor but also as a muscle growth factor that is involved in overloadinduced muscle hypertrophy [17]. The $A C E \mathrm{D}$ allele is usually associated with higher $A C E$ activity, thereby potentially resulting in higher angiotensin II levels [16] and higher proportion of fast, glycolytic, type $2 \mathrm{X}$ muscle fibres [18]; as such, this allele could theoretically favour sprint/power-oriented performance. However, collectively association studies performed with elite sprint/ power athletes are inconclusive [19-24].
One of the limitations of most studies above, investigating the association between the ACTN3 R577X or the $A C E \mathrm{I} / \mathrm{D}$ genotype and sprint/power performance, is grouping together sprint and power athletes from heterogeneous mixed sport disciplines and events (e.g., sprinters, jumpers, throwers, swimmers, and team sport athletes). This approach, while understandable given the very low number of world-class sprinters, reduces the accuracy of the phenotype. Furthermore, to date, only one report involving World-class sprinters of African ancestry [11], has studied the association between ACTN3 R577X and $A C E$ I/D polymorphism and athletic status; the lack of positive findings was attributable, at least partly, to the very low frequency of the ACTN3 577XX and $A C E$ II genotypes in the African population, which almost eliminates the possibility of detecting an association. Here, we sought to address these limitations and provide deeper insights into the influence of the ACTN3 R577X and the $A C E \mathrm{I} / \mathrm{D}$ variants on sprint performance by using a quantitative collaborative approach and by studying the influence of genotype on actual sprint performance.

Therefore, the aim of the present study was to examine the association between the ACTN3 R577X and the ACE I/D variants and 100-, 200-m and 400-m best personal times, in a large, performance-homogenous, cohort of elite Australian, Brazilian, Greek, Jamaican, Italian, Polish, Russian, Lithuanian, Spanish and US sprinters.

\section{Methods \\ Participants}

A total of 555 personal best $100-\mathrm{m}, 200-\mathrm{m}$ and $400-\mathrm{m}$ sprint times of 346 elite pure sprinters from Australia, Brazil, Greece, Jamaica, Italy, Lithuania, Poland, Russia, Spain and US were analyzed (Tables 1 and 2). The sprinters from Australia, Greece, Poland, Lithuania and Russia were all Caucasians (189 male and 66 female) whereas a total of 91 male Brazilian, Jamaican, US, Italian and Spanish athletes were from African lineage. The sprinters' best personal records (tail wind $<2 \mathrm{~m} / \mathrm{s}$ when provided) in official competitions were found online (www.iaaf.org) or provided by coaches or the athletes themselves and independently corroborated (Tables 1 and 2). The sprinters' best personal sprint times, grouped according to ethnic-background (Caucasians / Africans mixed linage athletes were excluded) and event (100-, 200- or 400-m), were standardized and relatively expressed to the relevant current World record. We included only 'pure' sprinters with the personal sprint time within $15 \%$ of the current relevant World record of the examined event. Thus, the following world records were used to calculate the inclusion criterion: in the male sprinters of African ancestry, $9.58 \mathrm{~s}$ in $100-\mathrm{m}$ and $19.9 \mathrm{~s}$ in 200-m (current World record holder: Usain Bolt), and 
Table 1 The 100-m, 200-m and 400-m best sprint times (average+SD) in males according to ACTN3 R577X genotype distribution

\begin{tabular}{|c|c|c|c|c|c|c|}
\hline \multirow[b]{2}{*}{ Running event/Genotype } & \multicolumn{4}{|l|}{ Caucasians } & \multicolumn{2}{|l|}{ African Ancestry } \\
\hline & $\mathrm{RR}$ & RX & $x X$ & $R R+D D+R X$ & $\mathrm{RR}$ & $\mathrm{RX}$ \\
\hline 100 m Male & $10.55 \pm 0.27(n=35)$ & $10.58 \pm 0.33(n=44)$ & $10.77 \pm 0.31(n=10)$ & $10.56 \pm 0.32(n=47)$ & $10.26 \pm 0.35(n=22)$ & $10.28 \pm 0.30(n=11)$ \\
\hline 200 m Male & $21.19 \pm 0.53(n=35)$ & $21.29 \pm 0.61(n=36)$ & $21.86 \pm 0.54^{*}(n=8)$ & $21.17 \pm 0.52(n=41)$ & $20.53 \pm 0.64(n=23)$ & $20.98 \pm 0.72(n=11)$ \\
\hline $400 \mathrm{~m}$ Male & $46.90 \pm 1.29(n=44)$ & $47.41 \pm 1.43(n=46)$ & $47.55 \pm 1.42(n=9)$ & $46.82 \pm 1.28(n=43)$ & $46.49 \pm 1.66(n=18)$ & $47.29 \pm 1.69(n=7)$ \\
\hline
\end{tabular}

*200-m (RR vs. RX vs. XX) $P<0.016$

43.18-s in 400-m (current World record holder: Michael Johnson); in female sprinters of African ancestry, $10.49 \mathrm{~s}$ in $100 \mathrm{~m}$ and $21.34 \mathrm{~s}$ in 200-m (current World record holder: Florence Griffith-Joyner); in the Caucasian male sprinters, $9.99 \mathrm{~s}$ in 100-m (best record holder: Christophe Lemaitre), $19.72 \mathrm{~s}$ in 200-m (best record holder: Pietro Mennea), and $43.45 \mathrm{~s}$ in $400-\mathrm{m}$ (best record holder: Jeremy Wariner); and in female Caucasian sprinters, 10.77-s in 100-m (best record holder: Ivet Lalova) and $21.71 \mathrm{~s}$ and $47.60 \mathrm{~s}$ in $200-\mathrm{m}$ and $400-\mathrm{m}$ respectively (best World record holder: Marita Koch).

\section{Genotyping}

Genomic DNA was isolated from buccal epithelium, or white blood cells. The Australian, Greek, Italian, Lithuanian, US, Jamaican, Russian (from St Petersburg) and Spanish sprinters' DNA samples were genotyped using the polymerase chain reaction (PCR)-restriction fragment length polymorphism (RFLP) method as previously described [4].

The DNA samples of the Polish, Brazilian, Russian (from Chelyabinsk), were genotyped in duplicates using an allelic discrimination assay on a Step One RealTime PCR instrument (Applied Biosystems, Carlsbad, California, USA) with Taqman ${ }^{\circ}$ probes. To discriminate ACTN3 R577X (rs1815739) alleles, TaqMan ${ }^{\circ}$ Pre-Designed SNP Genotyping Assay was used (assay ID: C_590093_1_), including appropriate primers and fluorescently labeled (FAM and VIC) MGB $^{\text {tw }}$ probes to detect the alleles.

Genotyping of the ACE I/D polymorphism, in all cohorts, was carried out as previously described [25].

\section{Statistical analysis}

To compare the sprinters' records between all genotypes we used the one-way analysis of variance (ANOVA). The Tukey's post-hoc test was used to determine statistical significant difference among the genotype groups. The level of significance was set at 0.05. Using the Simple Interactive Statistical Analysis website (SISA; www.quantitativeskills.com/sisa/) genotype interactions on sprint performance were further assessed using correlation analysis as previously described [26]. Briefly, three genetic models (additive model and two dominant models assuming complete dominance of each allele) were tested. The Additive genetic model consisted of $0,0.5$ and 1 , to represent $\mathrm{R}$ allele homozygotes, RX heterozygotes and homozygotes for the $\mathrm{X}$ allele, respectively; for the $\mathrm{R}$ allele dominant or $\mathrm{X}$ allele dominant genetic models, the corresponding values were $0,0,1$ or $0,1,1$, respectively. The proportion of the genetic contribution to phenotypic variance explained by each genetic model was estimated by expressing $r^{2}$ from the correlation analyses (taken as an estimate of percentage variance explained under the model) as a percentage of the variance explained by genotype effects in the modelfree ANOVAs. This proportion was compared for each model to predict the most accurate model tested.

\section{Results}

The personal best 100-, 200- and 400-m sprint times ( $\pm \mathrm{SD})$, according to the $A C T N 3$ and $A C E$ genotype and distribution, are presented in Tables 1 and 2.

Table 2 The 100-m, 200-m and 400-m best sprint times (average \pm SD) in males according to ACE I/D genotype distribution

\begin{tabular}{|c|c|c|c|c|c|c|c|}
\hline \multirow[b]{2}{*}{ Running event/Genotype } & \multicolumn{4}{|l|}{ Caucasians } & \multicolumn{3}{|c|}{ African Ancestry } \\
\hline & DD & ID & $\|$ & $X X+11+I D$ & DD & ID & ॥ \\
\hline 100 m Male & $\begin{array}{l}10.62 \pm 0.32 \\
(n=33)\end{array}$ & $\begin{array}{l}10.60 \pm 0.29 \\
(n=28)\end{array}$ & $\begin{array}{l}10.70 \pm 0.30 \\
(n=13)\end{array}$ & $\begin{array}{l}10.63 \pm 0.29 \\
(n=42)\end{array}$ & $\begin{array}{l}10.07+0.38 \\
(n=5)\end{array}$ & $\begin{array}{l}10.27+0.32 \\
(n=13)\end{array}$ & $\begin{array}{l}10.35+0.49 \\
(n=6)\end{array}$ \\
\hline 200 m Male & $\begin{array}{l}21.33 \pm 0.56 \\
(n=27)\end{array}$ & $\begin{array}{l}21.25 \pm 0.51 \\
(n=24)\end{array}$ & $\begin{array}{l}21.93 \pm 0.67^{* *} \\
(n=11)\end{array}$ & $\begin{array}{l}21.47 \pm 0.64^{* *} \\
(n=36)\end{array}$ & $\begin{array}{l}20.53+0.70 \\
(n=9)\end{array}$ & $\begin{array}{l}20.47+0.57 \\
(n=11)\end{array}$ & $\begin{array}{l}21.16+0.42 \\
(n=4)\end{array}$ \\
\hline 400 m Male & $\begin{array}{l}46.94 \pm 1.19 \\
(n=35)\end{array}$ & $\begin{array}{l}47.24 \pm 1.40 \\
(n=43)\end{array}$ & $\begin{array}{l}48.50 \pm 1.07^{* *} \\
(n=11)\end{array}$ & $\begin{array}{l}47.49 \pm 1.44^{* *} \\
(n=58)\end{array}$ & $\begin{array}{l}46.57+1.7 \\
(n=11)\end{array}$ & $\begin{array}{l}47.08+1.29 \\
(n=7)\end{array}$ & $\begin{array}{l}46.85+1.52 \\
(n=4)\end{array}$ \\
\hline
\end{tabular}

**200-m (DD vs. ID vs. II) $P<0.004 ; * * 400-m$ (DD vs. ID vs. II) $P<0.003$

${ }^{* *} 200-\mathrm{m}\left(\mathrm{RR}+\mathrm{DD}+\mathrm{RX}\right.$ see Table 1 vs. XX + II + ID) $P<0.002 ;{ }^{*} 400-\mathrm{m}(\mathrm{RR}+\mathrm{DD}+\mathrm{RX}$ see Table 1 vs. XX + II + ID) $P<0.001$ 
ACTN3 and ACE genotypes influence $200-\mathrm{m}$ best-personal sprint time in male athletes

In male Caucasian sprinters a significant association was detected between ACTN3 genotype and $200 \mathrm{~m}$ bestpersonal sprint time. Using Tukey's Multiple Comparison Test both ACTN3 577RR, $(-0.66,95 \%$ CI -0.20 to $-0.12)$ and 577RX $(-0.56,95 \% \mathrm{CI}-1.10$ to -0.02$)$ individuals were significantly faster than $577 \mathrm{XX}$ individuals $(P<0.05)$. We found the $\mathrm{R}$ allele dominant model $(\mathrm{RR} /$ RX vs. XX) had the best fit explaining $9.65 \%$ of sprint time $(P=0.005)$, compared to the additive $(7.28 \%, P=$ $0.01)$ and the $\mathrm{X}$ allele dominant model $(2.77 \%, P>0.05)$ in the correlation analysis. The percentage of the observed variance (coefficient of determination, $r^{2}$ ) explained by the $A C T N 3$ genotype using this recessive model was $0.92 \%$. The ACTN3 RR and ACTN3 RX groups were not significantly different, indicating the presence of one or two $\mathrm{R}$ allele does not have a dose dependant effect on $200 \mathrm{~m}$ sprint speed in elite athletes (Fig. 1a). In elite male African athletes $(n=92)$, there was some evidence for a dose effect of the ACTN3 R allele and $200 \mathrm{~m}$ sprint speed (Table 1). Using an unpaired $t$-test, the $A C T N 3 \mathrm{RR}$ individuals had (on average) a faster best-personal sprint time than ACTN3 RX individuals $(-0.45,95 \% \mathrm{CI}, 0.95$ to -0.04$)$.

In male Caucasian sprinters a significant association was detected between the $A C E$ genotype and $200 \mathrm{~m}$ sprint time. Using Tukey's Multiple Comparison Test both $A C E$ DD, $(-0.60,95 \% \mathrm{CI}-1.09$ to -0.11$)$ and $A C E$ ID $(-0.68$, $95 \% \mathrm{CI}-1.18$ to -0.18$)$ individuals had significantly faster sprint time than ACE II individuals $(P<0.05)$. Again, coding the genotypes to test gene models found the $\mathrm{D}$ allele dominant model (DD/ID vs. II) had the best fit explaining $16.4 \%$ of variance $(P=0.001)$, compared to the additive $(8.0 \%, P=0.02)$ and the I allele dominant $(1.2 \%, P>0.05)$ model. The percentage of observed variance (coefficient of determination, $\mathrm{r}^{2}$ ) explained by the $A C E$ genotype using this recessive model was $1.48 \%$ (Fig. 1b).
ACTN3 and ACE genotypes influence $400-\mathrm{m}$ best-personal sprint time in elite male athletes

In male Caucasian sprinters a significant association was detected between the $A C E$ genotype and 400-m sprint time. Using Tukey's Multiple Comparison Test both $A C E$ DD, $(-1.55,95 \% \mathrm{CI}-2.61$ to -0.48$)$ and $A C E$ ID $(-1.25,95 \%$ CI -2.29 to -0.21$)$ individuals had significantly faster sprint time than II individuals $(P<0.05)$. Using genetic models we found, again, that the $\mathrm{D}$ allele dominant model (DD/ID vs. II) had the best fit explaining $11.39 \%$ of $400 \mathrm{~m}$ sprint time $(P=0.001)$, compared to the additive $(9.78 \%, P=0.002)$ and I allele dominant (3.97\%, $P>0.05)$. The percentage of observed variance (coefficient of determination, $\mathrm{r}^{2}$ ) explained by the $A C E$ genotype using this recessive model was $1.48 \%$.

The $A C E$ DD and $A C E$ ID groups were not significantly different in sprint time, indicating the presence of one or two D allele does not have a dose dependant effect on 400-m best-personal sprint time in elite athletes (Fig. 2b). No cases of $A C E$ II male sprinters with a bestpersonal 400-m sprint time faster than the Olympics qualifying time (45.90s) were noted.

\section{No genotype differences were detected in 100-m sprint performance in both Caucasian and African ancestry sprinters}

There was no statistical significant difference in 100-m best running times across the ACTN3 R577X and $A C E$ I/D genotypes (Figs. $3 \mathrm{a}$ and b). Caucasian $(n=66)$ females were assessed separately and showed similar running times to males, across genotypes.

\section{No cumulative genotype effect on 200-m sprint performance}

In male Caucasian sprinters, a significant interaction was detected between the genotype combination of $A C T N 3 \mathrm{RR} / \mathrm{RX}$ and $A C E \mathrm{DD}$ with $200-\mathrm{m}$ sprint speed (Tables 1 and 2). Given we have found a positive


Fig. 1 a Individual 200-m running times ( \pm SD) in male Caucasian sprinters according to their ACTN3 R577X genotype and the qualifying times (QT) for the Olympic Games (20.65 s). b Individual 200-m running times ( \pm SD) in male Caucasian sprinters according to their ACE I/D genotype and the qualifying times (QT) for the Olympic Games (20.65 s) 

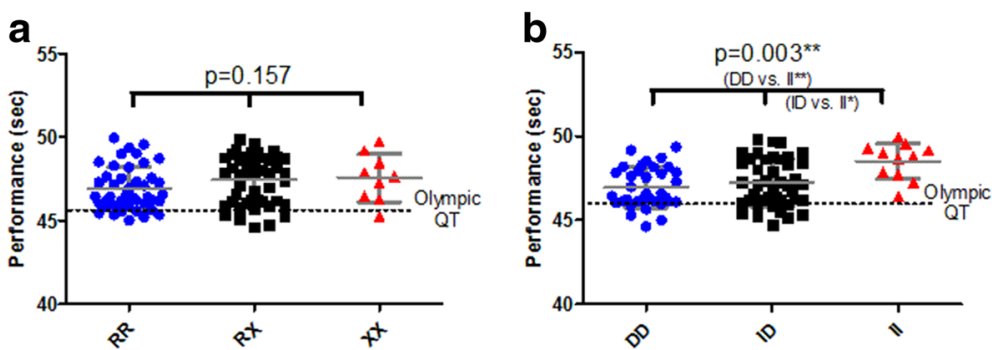

Fig. 2 a Individual 400-m running times ( $( \pm D D)$ in male Caucasian sprinters according to their ACTN3 R577X genotype and the qualifying times (QT) for the Olympic Games (45.90s). b Individual 400-m running times ( \pm SD) in male Caucasian sprinters according to their ACE I/D genotype and the qualifying times (QT) for the Olympic Games (45.90s)

associations by independently examining the ACTN3 $\mathrm{RR} / \mathrm{RX}$ and the $A C E \mathrm{DD} / \mathrm{ID}$ genotypes in Caucasian male 200-m sprint performance, we wondered whether the combination of these positive genotypes would have a cumulative benefit to performance. A genotype score was applied $(R R / R X=2, D D / I D=2, X X=0, I I=0)$ and plotted against $200 \mathrm{~m}$ performance time. An ideally predisposed sprinter would receive 4; a less ideally predisposed 2 and an adversely predisposed 0 . Despite hypothesising that the $200 \mathrm{~m}$ sprint time would be faster with a higher genotype score, the slope was close to zero $\left(r^{2}=0.02\right)$. Hence, there was no evidence for additive effect of these variants on $200 \mathrm{~m}$ sprint speed (Additional file 1).

\section{Discussion}

In this quantitative assessment of genotype with qualifying time in 346 elite sprinters, we have shown that it is rare for humans with the $\alpha$-actinin-3 deficient (ACTN3 $577 \mathrm{XX}$ ) and the $A C E$ II genotypes to qualify for the 200$\mathrm{m}$, and 400-m competitions, respectively, at the Olympic Games. From all male sprinters' best personal times included in this study, there were no cases of 577XX sprinters who had faster best-personal running time than 2012 Olympic qualifying standard in 200-m (20.65 s), and no cases of $A C E$ DD sprinters who had bestpersonal running time faster than 2012 Olympic qualifying standard in 400-m (45.90s). Collectively, these findings suggest that the ACTN3 $577 \mathrm{XX}$ and the $A C E$ II genotypes are detrimental for 200- and 400-m sprint performance respectively.

In the present study, we have addressed some of the limitations inherent in previous athlete case-control studies regarding the association between ACTN3 and $A C E$ genotypes and elite athletic performance. Firstly, we have studied ten cohorts of elite sprinters, including the fastest sprinters on earth. Consequently, the number of 'pure' elite sprinters $(n=346)$ in the present study is much larger compared to previous association studies, and demonstrates the benefits of a collaborative approach that has been recommended in the field of exercise genomics [1, 27, 28]. Secondly, previous reports have grouped together sprint and power athletes from mixed sports disciplines and events [3, 7-10, 28]. Here, we have embraced a more stringent approach and included only elite 'pure' sprinters whose main sporting event was the 100-, 200- or 400-m sprint event. Furthermore, we set explicit criteria (100-, 200- and 400-m best personal running times within $15 \%$ from the World record) to ensure a high performance level for the elite sprinters we studied. Thirdly, we have analysed quantitative measure with respect to $A C T N 3$ and $A C E$ genotypes to assess the genotype effect size in both males and females separately. Only one previous study has taken a similar approach with 100-m
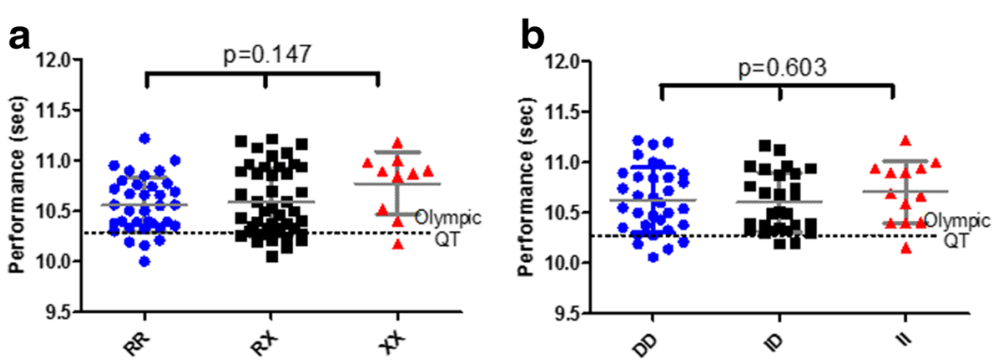

Fig. 3 a Individual 100-m running times ( $( \pm D$ ) in male Caucasian sprinters according to their ACTN3 R577X genotype and the qualifying times (QT) for the Olympic Games (10.24 s). b Individual 100-m individual running times ( \pm SD) in male Caucasian sprinters according to their ACE I/D genotype and the qualifying times (QT) for the Olympic Games (10.24-s) 
sprinters; a subgroup analysis of male Japanese track and field athletes indicated that those harbouring the ACTN3 577XX genotype ran the 100-m sprint significantly slower than their 577RX and 577RR counterparts [10]. However, this study was limited by its sample size $(n=28)$ and studied only Japanese cohort.

The analyses we performed show that the male Caucasian sprinters' best personal times are influenced by both $A C T N 3$ and $A C E$ genotypes in an event specific manner. While similar trends were seen in African and female athletes, we highlight that larger cohorts are urgently needed for adequate genotype-performance assessments. Our analyses on male Caucasian performances found that $200-$ or $400-\mathrm{m}$ (but not $100-\mathrm{m}$ performance) is influenced by both the ACTN3 and the ACE genotypes. Moreover, we showed that at the highest level of sprinting competition (i.e., elite sprinters who had bestpersonal sprint time faster than European or Olympic qualifying times) there was no significant overlap of the times for each genotype, suggesting that 'every variable counts' for achieving world-class sprinting performance. These findings, together with the separate results from 200 - and 400-m sprints support the notion that performance in the longer 200- and 400-m sprinting events is influenced by both ACTN3 R577X and ACE ID polymorphisms.

These genotype association differences may be related to subtle differences in the physiological performance demands of each event. In the $100-\mathrm{m}$ race the athlete is required to accelerate for most of the race before reaching their absolute maximum velocity [29]. In longer sprinting events (200- and 400-m) the acceleration phase is relatively shorter, and rather, it is the ability to maintain the maximum velocity for a longer time period that is the critical factor for winning the events [30]. Acceleration relies on reaction time, centre of gravity of the body relative to the blocks, frequency of step and step length, while maintaining absolute maximal velocity requires powerful cyclic muscle contractions and efficient utilization of the energy systems (mostly lactic and 'alactic' anaerobic systems) that are triggered at different phases of the race [31]. Given the genotype-performance associations at longer (200- and 400-m) distances, this suggests their influence may lie greater effect on muscle's metabolic potential (switch from $\mathrm{P} / \mathrm{Cr}$ to lactic anaerobic systems) with repeated powerful contractions.

The Actn3 knockout (KO) mouse has provided a possible explanation for the detrimental effect of $\alpha$-actinin-3 deficient (577XX genotype) on elite sprinting performance. Mechanistic studies in the Actn3 KO mouse show that this model mimics ACTN3 $X X$ in humans. The wild-type WT mice that express Actn3 (equivalent to human RR/RX genotypes) prefer the anaerobic system while Actn3 KO mice prefer the aerobic system.
Metabolically, the $\mathrm{KO}$ mice have significantly higher activity of oxidative enzymes, and lower activity in enzymes of the anaerobic pathway. In addition, they have enhanced glycogen accumulation due to lower glycogen phosphorylase activity has been observed [32, 33]. Their fast fibre properties shift towards a slower metabolic profile which has been linked to increases in calcineurin signalling activity [34] and altered calcium handling [35]. Overall this shift towards a slower physiological and metabolic profile would be detrimental to sprint performance in ACTN3 577XX humans [12, 32].

While a similar mechanistic model of the ACE genotype does not exist, a possible explanation for the metabolic effect of the $A C E$ genotype on sprint velocity performance may be related to fibre-type differences. Zhang et al. [18], has showed that the ACE II genotype is associated with higher percentage of type I, aerobicoriented, muscle fibres while the ACE DD genotype would be linked with a higher percentage of type $2 \mathrm{X}$, more anaerobic-oriented muscle fibres. While, more studies are required to fully elucidate the mechanism behind the potential association between the $A C E$ genotype and human elite sprint performance, it is interesting to note that both $A C T N 3$ and $A C E$ variants may independently affect muscle fibre metabolism.

An additional exploration in the present study was testing whether sprinters with the theoretical 'favourable' genotypes for ACE (DD/ID) and ACTN3 (RR/RX) had cumulative effects on performance speed. While we did find a significant interaction for the $A C E$ and ACTN3 genotypes and sprint time (Tables 1 and 2), we have subsequently scored these variants and plotted against $200 \mathrm{~m}$ sprint time, and could not detect evidence for additive effect on $200 \mathrm{~m}$ sprint speed. Given the limited number of athletes with the ACTN3 $\mathrm{XX}+A C E$ II genotype (and no dose dependant allele differences in RR/RX and DD/ID), as well as performance times that are approaching the limits of human performance, testing for measurable cumulative performance benefits in these elite cohorts maybe difficult to achieve.

Despite no evidence for cumulative performance benefits for the $A C E$ and ACTN3 variants, both genes have been repeatedly shown to be altered in frequency in elite athletes compared to controls. Given these associations, the notion that elite performance is a polygenic trait by nature (e.g., a phenotypic trait produced by multiple genes working together), with a minor contribution of each variant to the unique athletic phenotype, remains supported. While probability of becoming an elite athlete is thought to increase based upon having a greater number of athletic-related alleles [36-38], our initial scoring in male Caucasians demonstrates that it may 
be difficult to ascertain cumulative contributions to performance.

Here, we have shown for the first time quantitatively that the ACTN3 and ACE genotypes account for $~ 1-$ $1.5 \%$ in sprint speed amongst elite male athletes. This difference in sprint time is substantial at the elite level and can be the difference between a world record and only making the final 16 . Despite this, the predictive value of these tests remains limited. A substantial amount of performance variation remains unaccounted for and further research into both common and rare variants is still required.

\section{Conclusions}

In conclusion, our multi-centre study has enabled us to gain insights into the effect of ACTN3 and ACE genotypes on elite sprinting performance. Both ACTN3 R577X and $A C E$ ID polymorphisms modulate specific sprint phenotypes and influence the athletic status at the extremes of human performance. While the ACTN3 R577X polymorphism seems to be more influential to 200-m performance, the $A C E$ ID polymorphism would be more involved in the longer, 400-m sprint performance. With greater knowledge of both common and rare performance variants these findings might have future applications for identifying and coaching talented 200and 400-m sprinters.

\section{Ethics statement}

Ethical approval was obtained from the Human Research Ethics Committees of the Children's Hospital at Westmead (2003/086), RCH Human Research Ethics Committee (35172), The Lithuanian National Committee of Biomedical Ethics, The Ethics Committee of St. Petersburg State University, The Ethics Research Committee of the University of Sao Paulo, The Ural State University of Physical Culture Ethics Committee, The Universidad Pablo Olavide Research Committee, The Ethics committee of Pomeranian Medical University, Aristotle University of Thessaloniki Research Committee, The Ethics Committee of the University of Cagliari, and UHWI/UWI/FMS Ethics Committee. All studies were conducted in accordance with the ethical standard laid down in the 1964 Declaration of Helsinki and its later amendments and all participants have signed a consent form.

\section{Additional file}

Additional file 1: No cumulative genotype effect on 200-m sprint performance. (PNG $6 \mathrm{~kb}$ )

Competing interests

The authors declare that they have no competing or financial interests.

\section{Authors' contributions}

IDP: conceived the idea, done the analysis and contributed in data collection and interpretation of the results. $A L, F G, N E, D B, G W, Y P P \vee P P, D D, E F O, K N$, GGA, JPFLG, AHLJ, VG, PC, AMK, MS, CAM, AK, MM, CMC, PJH, AK, AMD, IA, IIA: involved in data collection, revised the manuscript and made substantial contributions in interpretation of the results. All authors read and approved the final manuscript

\section{Acknowledgments}

No funding was received to assist in the preparation of this manuscript. The authors have no conflicts of interest to declare that are directly relevant to the content of this manuscript. The Authors declare that they have full control of the primary data and they agree to allow the journal to review their data if requested. IDP wishes to dedicate this paper to Prof. C.

Triantafyllidis and Prof. V. Klissouras.

\section{Author details}

${ }^{1}$ Institute of Sport, Exercise and Active Living (ISEAL), Victoria University, Victoria 8001, Australia. ${ }^{2}$ Universidad Europea and Research Institute Hospital 12 de Octubre, Madrid, Spain. ${ }^{3}$ FIMS Reference Collaborating Centre of Sports Medicine for Anti-Doping Research, University of Brighton, Brighton, UK. ${ }^{4}$ Clinical Physiology Laboratory, Urals Research Centre for Radiation Medicine, Chelyabinsk, Russia. ${ }^{5}$ Ural State University of Physical Culture, Chelyabinsk, Russia. ${ }^{6}$ School of Physical Education and Sport, University of Sao Paulo, Sao Paulo, Brazil. Department of Human and Medical Genetics, Vilnius University, Vilnius, Lithuania. ${ }^{8}$ Department of Physical Culture and Health Promotion, University of Szczecin, Szczecin, Poland. ${ }^{9}$ Faculty of Physical Activity, Universidad Europea de Madrid, Alcobendas, Spain. ${ }^{10}$ Department of Genetics, Development and Molecular Biology, Aristotle University of Thessaloniki, Thessaloniki, Greece. ${ }^{11}$ Department of Life and Environmental Sciences, University of Cagliari, Cagliari, Italy. ${ }^{12}$ Sports Genetics Laboratory, St Petersburg Research Institute of Physical Culture, St. Petersburg, Russia. ${ }^{13}$ Department of Physiology, St Petersburg State University, St. Petersburg, Russia. ${ }^{14}$ Sport Technology Research Centre, Volga Region State Academy of Physical Culture, Sport and Tourism, Kazan, Russia. ${ }^{15}$ Murdoch Childrens Research Institute, Melbourne, Australia. ${ }^{16}$ Department of Sport Education, Academy of Physical Education and Sport, Gdansk, Poland.

Received: 9 August 2015 Accepted: 11 February 2016 Published online: 13 April 2016

\section{References}

1. Pitsiladis Y, Wang G, Wolfarth B, Scott R, Fuku N, Mikami E, He Z, Fiuza-Luces C, Eynon N, Lucia A: Genomics of elite sporting performance: what little we know and necessary advances. Br J Sports Med. 2013;47(9):550-5.

2. Eynon N, Hanson ED, Lucia A, Houweling PJ, Garton F, North KN, et al. Genes for elite power and sprint performance: ACTN3 leads the way. Sports Med. 2013;43:803-17.

3. Yang N, MacArthur DG, Gulbin JP, Hahn AG, Beggs AH, Easteal S, et al. ACTN3 genotype is associated with human elite athletic performance. Am J Hum Genet. 2003;73:627-31.

4. Mills M, Yang N, Weinberger R, Vander Woude DL, Beggs AH, Easteal $S$, et al. Differential expression of the actin-binding proteins, alpha-actinin-2 and -3 , in different species: implications for the evolution of functional redundancy. Hum Mol Genet. 2001;10:1335-46.

5. North KN, Yang N, Wattanasirichaigoon D, Mills M, Easteal S, Beggs AH. A common nonsense mutation results in alpha-actinin-3 deficiency in the general population. Nat Genet. 1999;21:353-4.

6. Niemi A-K, Majamaa K. Mitochondrial DNA and ACTN3 genotypes in Finnish elite endurance and sprint athletes. Eur J Hum Genet. 2005;13:965-9.

7. Papadimitriou ID, Papadopoulos C, Kouvatsi A, Triantaphyllidis C. The ACTN3 gene in elite Greek track and field athletes. Int J Sports Med. 2008;29:352-5.

8. Druzhevskaya AM, Ahmetov II, Astratenkova IV, Rogozkin VA. Association of the ACTN3 R577X polymorphism with power athlete status in Russians. Eur J Appl Physiol. 2008:103:631-4.

9. Eynon N, Duarte JA, Oliveira J, Sagiv M, Yamin C, Meckel Y, et al. ACTN3 R577X Polymorphism and Israeli Top-level Athletes. Int J Sports Med. 2009; 30:695-8. 
10. Mikami E, Fuku N, Murakami H, Tsuchie H, Takahashi H, Ohiwa N, et al. ACTN3 R577X Genotype is associated with sprinting in elite japanese athletes. Int J Sports Med. 2014;35(2):172-7.

11. Scott RA, Irving R, Irwin L, Morrison E, Charlton V, Austin K, et al. ACTN3 and ACE genotypes in elite Jamaican and US sprinters. Med Sci Sports Exerc. 2010:42:107-12.

12. MacArthur DG, Seto JT, Chan S, Quinlan KG, Raftery JM, Turner N, et al. An Actn3 knockout mouse provides mechanistic insights into the association between alpha-actinin-3 deficiency and human athletic performance. Hum Mol Genet. 2008;17:1076-86.

13. Vincent B, De Bock K, Ramaekers M, Van den Eede E, Van Leemputte M, Hespel P, et al. ACTN3 (R577X) genotype is associated with fiber type distribution. Physiol Genomics. 2007;32:58-63.

14. Ahmetov I, Druzhevskaya AM, Lyubaeva EV, Popov DV, Vinogradova OL, Williams AG. The dependence of preferred competitive racing distance on muscle fibre type composition and ACTN3 genotype in speed skaters. Exp Physiol. 2011;96(12):1302-10.

15. Ahmetov II, Donnikov AE, Trofimov DY. ACTN3 genotype is associated with testosterone levels of athletes. Biol Sport. 2014;31:105-8.

16. Jones A, Montgomery HE, Woods DR. Human performance: a role for the ACE genotype? Exerc Sport Sci Rev. 2002;30:184-90.

17. Gordon SE, Davis BS, Carlson CJ, Booth FW. ANG II is required for optimal overload-induced skeletal muscle hypertrophy. Am J Physiol-Endocrinol Metab. 2001;280:E150-9.

18. Zhang B, Tanaka H, Shono N, Miura S, Kiyonaga A, Shindo M, et al. The I allele of the angiotensin-converting enzyme gene is associated with an increased percentage of slow-twitch type I fibers in human skeletal muscle. Clin Genet. 2003:63:139-44.

19. Myerson S, Hemingway $H$, Budget R, Martin J, Humphries S, Montgomery $H$. Human angiotensin I-converting enzyme gene and endurance performance. J Appl Physiol. 1999;87:1313-6.

20. Taylor RR, Mamotte CD, Fallon K, van Bockxmeer FM: Elite athletes and the gene for angiotensin-converting enzyme. J Appl Physiol Bethesda Md 1985. 1999:87:1035-37.

21. Nazarov IB, Woods DR, Montgomery HE, Shneider OV, Kazakov VI, Tomilin NV, et al. The angiotensin converting enzyme I/D polymorphism in Russian athletes. Eur J Hum Genet. 2001;9:797-801.

22. Amir O, Amir R, Yamin C, Attias E, Eynon N, Sagiv M, et al. The ACE deletion allele is associated with Israeli elite endurance athletes: The ACE deletion allele in elite athletes. Exp Physiol. 2007:92:881-6.

23. Papadimitriou ID, Papadopoulos C, Kouvatsi A, Triantaphyllidis C. The ACE I/ D polymorphism in elite Greek track and field athletes. J Sports Med Phys Fitness. 2009;49:459-63.

24. Massidda M, Corrias L, Scorcu M, Vona G, Calò MC. ACTN-3 and ACE genotypes in elite male Italian athletes. Anthropol Rev. 2013;75(1):51-59.

25. Rigat B, Hubert C, Alhenc-Gelas F, Cambien F, Corvol P, Soubrier F. An insertion/deletion polymorphism in the angiotensin l-converting enzyme gene accounting for half the variance of serum enzyme levels. J Clin Invest. 1990:86:1343-6.

26. Moran CN, Yang N, Bailey ME, Tsiokanos A, Jamurtas A, MacArthur DG, et al. Association analysis of the ACTN3 R577X polymorphism and complex quantitative body composition and performance phenotypes in adolescent Greeks. Eur J Hum Genet. 2007;15:88-93.

27. Eynon N, Ruiz JR, Oliveira J, Duarte JA, Birk R, Lucia A. Genes and elite athletes: a roadmap for future research. J Physiol. 2011;589:3063-70.

28. Eynon N, Ruiz JR, Femia P, Pushkarev VP, Cieszczyk P, Maciejewska-Karlowska A, et al. The ACTN3 R577X polymorphism across three groups of elite male European athletes. PLoS One. 2012;7, e43132.

29. Morin J-B, Bourdin M, Edouard P, Peyrot N, Samozino P, Lacour J-R. Mechanical determinants of 100-m sprint running performance. Eur J Appl Physiol. 2012;112:3921-30.

30. Hanon C, Gajer B. Velocity and stride parameters of world-class 400-meter athletes compared with less experienced runners. J Strength Cond Res Natl Strength Cond Assoc. 2009;23:524-31.

31. Bret $C$, Lacour J-R, Bourdin M, Locatelli E, De Angelis M, Faina M, et al. Differences in lactate exchange and removal abilities between high-leve African and Caucasian 400-m track runners. Eur J Appl Physiol. 2013;113: 1489-98.

32. MacArthur DG, North KN. ACTN3: A genetic influence on muscle function and athletic performance. Exerc Sport Sci Rev. 2007:35:30-4.
33. Quinlan KG, Seto JT, Turner N, Vandebrouck A, Floetenmeyer M, Macarthur DG, et al. Alpha-actinin-3 deficiency results in reduced glycogen phosphorylase activity and altered calcium handling in skeletal muscle. Hum Mol Genet. 2010;19:1335-46.

34. Seto JT, Quinlan KGR, Lek M, Zheng XF, Garton F, MacArthur DG, et al. ACTN3 genotype influences muscle performance through the regulation of calcineurin signaling. J Clin Invest. 2013;123:4255-63.

35. Head SI, Chan S, Houweling PJ, Quinlan KGR, Murphy R, Wagner S, et al. Altered $\mathrm{Ca} 2+$ kinetics associated with a-Actinin-3 deficiency may explain positive selection for ACTN3 null allele in human evolution. PLOS Genet. 2015;11.

36. Ahmetov II, Williams AG, Popov DV, Lyubaeva EV, Hakimullina AM, Fedotovskaya ON, et al. The combined impact of metabolic gene polymorphisms on elite endurance athlete status and related phenotypes. Hum Genet. 2009:126:751-61.

37. Hughes DC, Day SH, Ahmetov II, Williams AG. Genetics of muscle strength and power: polygenic profile similarity limits skeletal muscle performance. J Sports Sci. 2011:29:1425-34

38. Tucker $\mathrm{R}$, Collins M. What makes champions? a review of the relative contribution of genes and training to sporting success. Br J Sports Med. 2012;46:555-61.

\section{Submit your next manuscript to BioMed Central and we will help you at every step:}

- We accept pre-submission inquiries

- Our selector tool helps you to find the most relevant journal

- We provide round the clock customer support

- Convenient online submission

- Thorough peer review

- Inclusion in PubMed and all major indexing services

- Maximum visibility for your research

Submit your manuscript at www.biomedcentral.com/submit

) Biomed Central 